\title{
PELATIHAN PEMBUATAN SERBUK MINUMAN HERBAL INSTAN UNTUK WARGA DESA JAJAR, KECAMATAN TALUN, KABUPATEN BLITAR
}

\author{
Oleh: \\ Ismono ${ }^{1}$, Suyatno ${ }^{2}$, Nurul Hidajati ${ }^{3}$ \\ 1,2,3Jurusan Kimia FMIPA Unesa \\ 1ismono@unesa.ac.id
}

\begin{abstract}
Abstrak
Desa Jajar, merupakan salah satu desa di kecamatan Talun, kabupaten Blitar merupakan wilayah yang sedang berkembang, sebagian warga desa tersebut bekerja sebagai petani, buruh tani, tukang kayu, tukang batu, kuli bangunan, penjual sayur keliling, membuka warung makanan dan merancang, serta pegawai pemerintah dan swasta. Dengan demikian sebagian besar warga memiliki penghasilan yang paspasan untuk memenuhi kebutuhan hidup. Warga desa Jajar sangat memerlukan pelatihan suatu keterampilan dalam upaya untuk meningkatkan pendapatan ekonomi keluarganya. Salah satu jenis pelatihan yang dapat diberikan adalah pelatihan pembuatan serbuk minuman herbal instan. Produk minuman memiliki potensi ekonomi untuk meningkatkan penghasilan keluarga. Kegiatan PKM dimaksudkan untuk meningkatkan keterampilan warga desa Jajar dalam membuat minuman herbal yang memiliki dampak kesehatan dan nilai ekonomi. Kegiatan PKM melibatkan 30 orang ibu rumah tangga desa Jajar. Pendekatan yang digunakan dalam PKM ini adalah pendekatan partisipasif, sedangkan metode yang diterapkan adalah pendampingan pembelajaran orang dewasa (andragogi).

Kegiatan PKM akan diawali dengan pemaparan materi pelatihan oleh Tim PKM, dilanjutkan dengan pendampingan praktek pembuatan minuman serbuk herbal instan, dan diakhiri dengan refleksi serta pemberian angket. Kegiatan PKM ini dapat menghasilkan luaran berupa produk serbuk minuman herbal instan kesehatan yang bermanfaat bagi masyarakat di desa Jajar, Kecamatan Talun, Blitar khususnya dari segi meningkatkan perekonomian keluarga.
\end{abstract}

Kata kunci: Minuman serbuk herbal instan, Desa Jajar

\begin{abstract}
Desa Jajar, one of the villages in Talun sub-district, Blitar district is an emerging area, some villagers work as farmers, farm workers, carpenters, masons, construction laborers, vegetable sellers, open food stalls and design, and public and private employees. Thus, most people have a mediocre income to meet the needs of life. The villagers of Jajar desperately need skills training in an effort to increase their family's income. One type of training that can be given is the training of making instant herbal beverage powder. Beverage products have the economic potential to increase family income. PKM activities are intended to improve the skills of Jajar village residents in making herbal drinks that have health impacts and economic value. PKM activities involve 30 housewives of Jajar village. The approach used in this PKM is participatory approach, while the method applied is adult learning assistance (andragogy).

PKM activities will begin with the presentation of training materials by the team, followed by the assistance of the practice of making instant herbal powder beverages, and ending with reflection and questionnaire. This PKM activity can produce outcomes in the form of instant health herbal beverage powder products that are beneficial to the community in Desa Jajar, Talun sub district, Blitar especially in terms of improving the family economy.
\end{abstract}

Keywords: Instant herbal drink mix, Desa Jajar

\section{PENDAHULUAN}

Indonesia merupakan salah satu negara yang memiliki kekayaan alam hayati yang beranekaragam (biodiversity). Salah satu kekayaan alam hayati tersebut berupa beranekaragam spesies tumbuhan, mulai dari tumbuhan tingkat rendah hingga tumbuhan tingkat tinggi (Achmad, dkk., 2007; Manito, 1992; Heyne, 1987). Handra (2005) menyatakan bahwa di Indonesia terdapat sekitar 30.000 spesies tanaman yang sebagian besar tersebar di wilayah hutan hujan tropis. Dari spesies tanaman tersebut, lebih dari 3300 spesies (11\%) merupakan tanaman yang mempunyai khasiat obat dan baru sekitar 300 spesies 
yang telah dimanfaatkan oleh masyarakat yang berupa obat tradisional (jamu) dan minuman kesehatan produk herbal.

Salah satu produk herbal yang telah dikenal masyarakat adalah serbuk jamu instan. Beberapa contoh produk serbuk jamu instan disajikan pada Gambar 1. Produk tersebut berbentuk serbuk sehingga bersifat praktis dan cepat dalam penyajiannya, serta memiliki daya simpan yang relatif lama. Serbuk jamu instan dibuat dengan menggunakan ekstrak tumbuhan obat yang banyak ditanam di sekitar rumah atau lebih dikenal dengan TOGA. Contoh TOGA yang banyak digunakan untuk memproduksi serbuk jamu instan adalah kunyit, kunyit putih, jahe, temulawak, dan temu mangga. Namun demikian tidak tertutup kemungkinan untuk membuat serbuk jamu instan menggunakan tanaman obat yang lain, misalnya daun pegagan (Angria, 2013; Anonim, 2013).

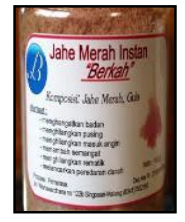

(a)

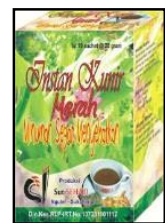

(b)
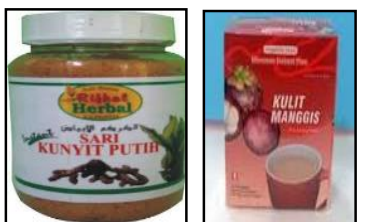

(c) (d)

Gambar 1 Beberapa Contoh Produk Serbuk Jamu Instan yang beredar di pasaran (a) Jahe merah (b) Kunir merah (c) Kunyit putih (d) Kulit manggis

Di samping dalam bentuk serbuk, minuman herbal instan dapat dibuat dalam bentuk cair, sebagai contoh sara'ba (minuman khas Makasar) dan sirup emponempon. Kedua jenis minuman tersebut dapat dibuat dari tanaman obat keluarga yang banyak ditanam di pekarangan rumah warga, seperti jahe, kunyit, temulawak, dan sereh. Minuman sara'ba dengan kandungan utama jahe, merica hitam, dan susu sangat baik untuk menambah stamina tubuh. Sementara itu sirup empon-empon dengan kandungan utama jahe, temulawak, kunyit, dan bunga rosella sangat baik untuk menambah nafsu makan, mejaga fungsi hati (hepatoprotektor), mencegah peradangan (antiinflamasi), mencegah kanker, dan bersifat antioksidan (Mallaleng, dkk., 2011; Mallaleng, dkk., 2012).

Desa Jajar merupakan salah satu desa yang berada di Kecamatan Talun, Kabupaten Blitar. Sebagai salah satu desa yang sedang berkembang di Blitar yang kaya akan tanaman herbal. Tanaman herbal banyak ditanam di lahan pertanian maupun di pekarangan rumah warga.

Tanaman herbal (TOGA) tersebut belum dimanfaatkan secara optimal, khususnya dalam bidang peningkatan kesehatan maupun nilai tambah dalam membantu meningkatkan perekonomian keluarga. Dengan demikian upaya pemberian pelatihan untuk memberikan bekal keterampilan kepada ibu rumah tangga warga desa Jajar sangat diperlukan untuk menambah pendapatan ekonomi rumah tangganya.

Dengan demikian kehadiran minuman alternatif yang berupa serbuk instan jahe, temulawak, serbuk instan secang, dan serbuk keji beling instan dapat menjadi pilihan untuk menjaga stamina dan kesehatan tubuh warga desa Jajar. Minuman ini di samping mengandung zat gizi, juga mengandung senyawa bioaktif yang bersifat melancarkan peredaran darah, menjaga fungsi hati, antiinflamasi, antikanker, dan antioksidan. Jika informasi ini dapat disampaikan dengan baik kepada konsumen maka minuman kesehatan berbasis herbal baik bentuk serbuk maupun cair sangat berpotensi untuk mendatangkan keuntungan finasial yang besar, sehingga mampu meningkatkan pendapatan ekonomi keluarga. Jika warga memiliki wawasan dan jiwa wirausaha, maka produksi minuman serbuk herbal instan dapat menjadi alternatif usaha yang memiliki prospek untuk meningkatkan penghasilan keluarga dan membuka lapangan kerja. Produk tersebut dapat dijual di warung makanan, toko jamu, apotik atau toko obat, serta dapat didistribusikan ke luar desa.

Berdasarkan hasil wawancara kami dengan ibu rumah tangga warga Desa Jajar, Kec. Talun, Blitar diperoleh informasi bahwa mereka belum berpengalaman membuat minuman kesehatan berbasis herbal baik bentuk serbuk. Sementara itu bahan untuk membuatnya banyak ditanaman di sekitar rumah warga atau dengan mudah dapat diperoleh di pasar terdekat. Banyaknya warung-warung makanan. toko, dan apotik yang berada di wilayah Desa Jajar, sangat mendukung penjualan produk minuman kesehatan berbasis herbal. Oleh karena itu dalam rangka membantu pemerintah, khususnya Pemkab Blitar maka kami bermaksud memberikan pelatihan kepada ibu-ibu 
rumah tangga warga Desa Jajar, Kecamatan Talun, Blitar untuk meningkatkan keterampilannya dalam pembuatan minuman kesehatan berbasis herbal yang hasilnya dapat berpotensi untuk meningkatkan pendapatan ekonomi keluarga. Di samping itu Tim PKM akan memberikan wawasan tentang wirausaha, manajemen usaha, dan teknik pengemasan agar peserta pelatihan memiliki motivasi, strategi, dan mampu mengelola produk minuman kesehatan berbasis herbal yang dihasilkan. Pembekalan teknik pengemasan juga diberikan agar produk yang dihasilkan lebih menarik bagi konsumen dan mampu bersaing dengan produk lain di pasaran.

Berdasarkan uraian latar belakang di atas maka permasalahan yang diusulkan melalui kegiatan pengabdian kepada masyarakat ini adalah bertujuan untuk mengetahui:

1. Keterampilan para ibu rumah tangga warga desa Jajar, Kec. Talun, Blitar dalam membuat minuman serbuk herbal instan setelah mengikuti kegiatan pelatihan?

2. Pemahaman para ibu rumah tangga warga desa Jajar, Kec. Talun, Blitar terhadap wirausaha, manajemen usaha, serta teknik pengemasan produk minuman serbuk herbal instan?

3. Respons para ibu rumah tangga warga desa Jajar, Kec. Talun, Blitar terhadap kegiatan pelatihan pembuatan minuman serbuk herbal instan?

\section{METODE PELAKSANAAN}

Jumlah peserta yang mengikuti pelatihan sekitar 30 orang warga ibu-ibu PKK desa Jajar. Metode yang digunakan adalah metode pratisipasi aktif pendampingan dalam proses pendampingan dan pelatihan pembuatan minuman kesehatan berbasis herbal menggunakan tanaman TOGA untuk membekali keterampilan para ibu rumah tangga di wilayah desa Desa Jajar, Kec. Talun, Kab. Blitar adalah sebagai berikut:

1. Menyusun atau menyiapkan buku panduan pembuatan minuman serbuk herbal instan

2. Pemaparan materi pembuatan minuman serbuk herbal instan, wawasan wirausaha, manajemen usaha, dan teknik pengemasan produk oleh Tim PKM
3. Memberikan contoh pembuatan minuman serbuk herbal instan dengan melibatkan peserta pelatihan menggunakan bahan-bahan yang telah disediakan

4. Praktek mandiri pembuatan minuman serbuk herbal instan yang dilakukan oleh ibu rumah tangga peserta pelatihan. Pada tahap ini peserta pelatihan dibagi menjadi lima kelompok (tiap kelompok beranggotakan 5-6 orang) dan tiap-tiap kelompok melakukan praktek pembuatan serbuk jahe instan, serbuk temulawak instan, serbuk secang instan, dan serbuk keji beling instan. Keterampilan peserta di tiap kelompok diukur menggunakan lembar penilaian kinerja.

5. Melakukan refleksi/umpan balik dan masukan/opini/pendapat dan saran mereka tentang hasil pelatihan yang telah dilaksanakan

\section{HASIL DAN PEMBAHASAN}

1. Pelaksanaan

Pelaksanaan PKM diawali dengan pembukaan dan perkenalan tim PKM dengan kepala desa dan warga peserta PKM. Kemudian dilakukan dilakukan pengarahan oleh kepala desa dan tim PKM, seperti yang terlihat pada gambar 2 dan 3 di bawah ini.

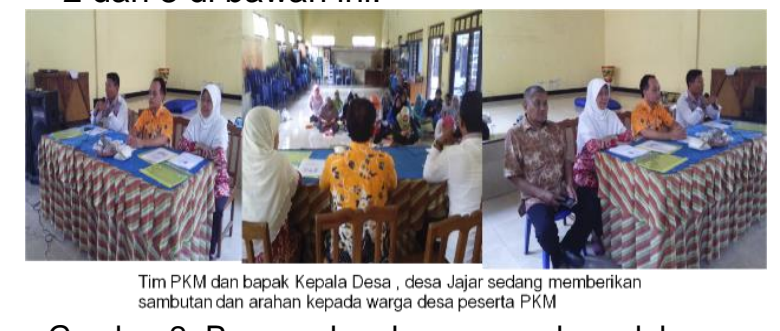

Gambar 2. Pengenalan dan pengarahan oleh kepala Desa dan tim PKM

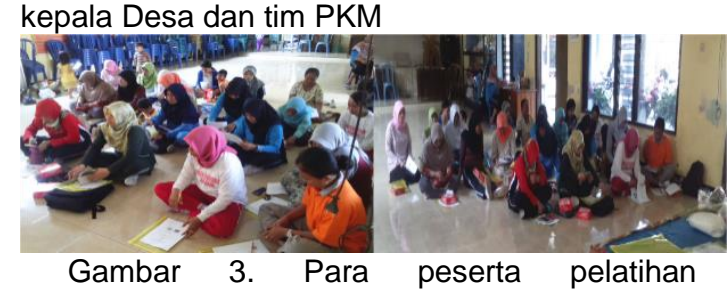

mendengarkan pengarahan dari tim PKM

Tim PKM memberikan pengarahan tentang tatacara mengikuti pelatihan dan tatacara membaca prosedur kerja tentang kegiatan yang akan dilaksanakan, serta langkah-langkah operasional pembuatan minuman herbal untuk kesehatan. 
Selama kegiatan pelatihan berlangsung para peserta pelatihan mengikuti kegiatan pelatihan dengan sabar, telaten, dan ceria. Kegiatan pelaksanaan penelitian juga melibatkan para pembimbing PKM untuk mendampingi para peserta pelatihan dalam membuat minuman herbal kesehatan seperti terlihat pada beberapa gambar 4 di bawah ini.
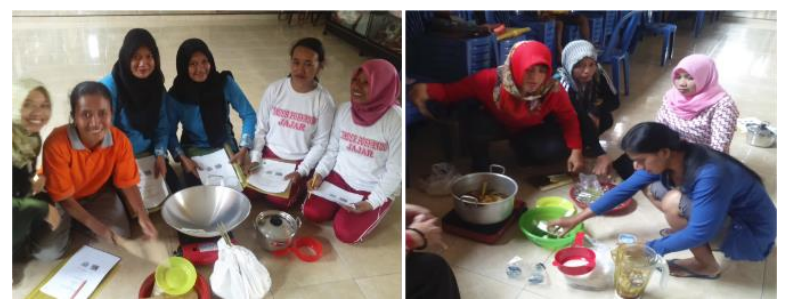

Gambar 4. Para peserta pelatihan melakukan persiapan untuk membuat minuman herbal

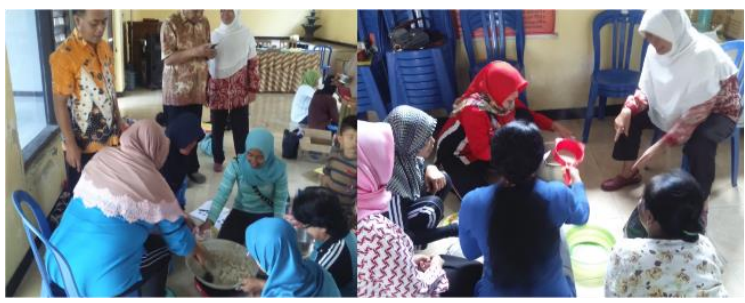

Gambar 5. Pembimbing memberikan bimbingan kepada peserta pelatihan

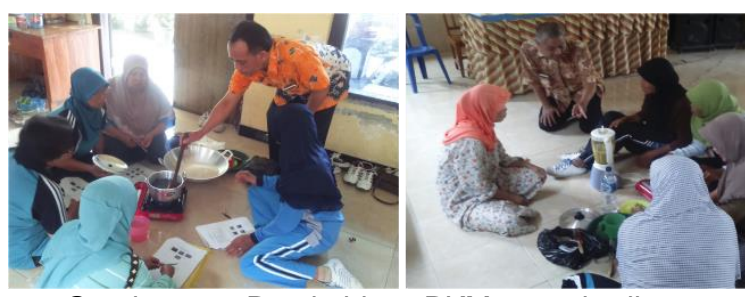

Gambar 6. Pemimbing PKM memberikan bimbingan, arahan dan bantuan bagi peserta yang mengalami kesulitan

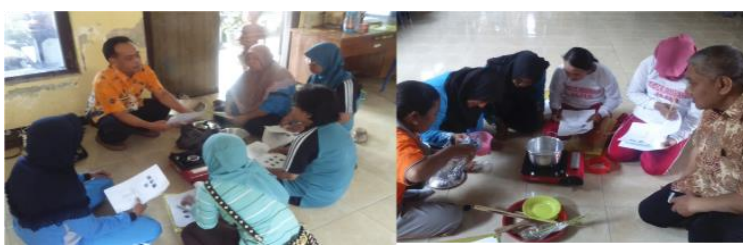

Gambar 7. Pemimbing PKM memberikan bimbingan, arahan dan bantuan bagi peserta yang mengalami kesulitan

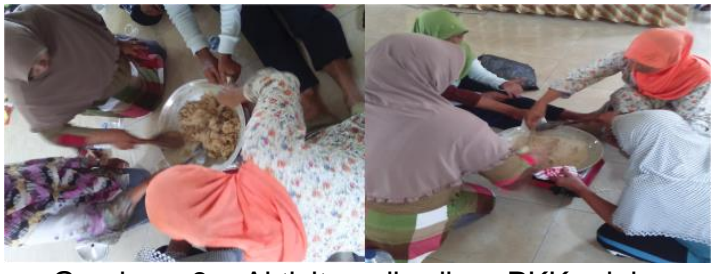

Gambar 8. Aktivitas ibu-ibu PKK dalam membuat serbuk minuman herbal

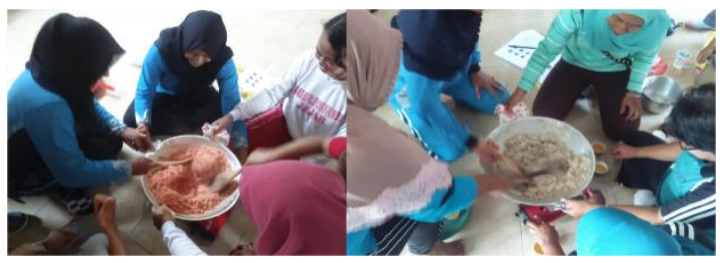

Gambar 9. Peserta pelatihan telah berhasil membuat minuman serbuk herbal

2. Hasil yang Dicapai

Sebelum dilakukan pelatihan, ibu-ibu peserta pelatihan diperkenal terlebih dahulu bahan-bahan dasar herbal yang digunakan seperti pada gambar 10

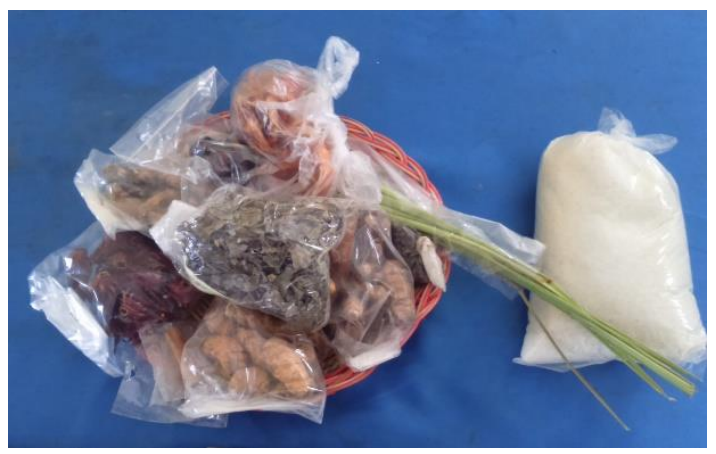

Gambar 10. Bahan dasar yang digunakan Pembuatan Serbuk Minuman Herbal Instan

Setelah dilakukan pelatihan pembuatan minuman herbal, para ibu-ibu PKK desa Jajar, Kecamatan Talun, kabupaten Blitar mampu membuat minuman herbal baik yang berupa instan (bentuk serbuk) dari bahan-bahan dasar pada gambar 10 . Produk yang dihasilkan oleh para ibu-ibu PKK seperti yang terlihat pada gambar 11 


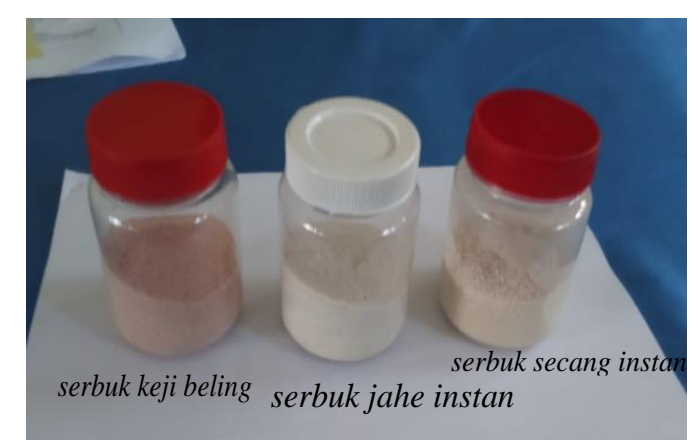

Gambar 11. Hasil Produk Pembuatan Serbuk Minuman Herbal Instan
Selama proses pelatihan dilakukan pengamatan aktivitas peserta pelatihan selama mengikuti pelatihan. Pengamatan dilakukan dengan menggunakan lembar pengamatan penilaian aktivitas peserta pelatihan. Data hasil pengamatan penilaian aktivitas peserta pelatihan dapat dilihat pada Tabel 1, Tabel 2, dan Tabel 3 di bawah ini.

Tabel 1. Penilaian Keterampilan Pembuatan Serbuk Jahe Instan

\begin{tabular}{c|l|c|c|c}
\hline No & \multicolumn{1}{c}{ Komponen yang diamati } & \multicolumn{3}{c}{ Skor Penilai } \\
\hline $\mathbf{1}$ & Mencuci rimpang jahe & 4 & 4 & 4 \\
\hline $\mathbf{2}$ & $\begin{array}{l}\text { Memotong rimpang jahe dengan pisau sehingga } \\
\text { berukuran kecil }\end{array}$ & 4 & 4 & 4 \\
\hline $\mathbf{3}$ & $\begin{array}{l}\text { Menghaluskan potongan rimpang jahe yang telah } \\
\text { dipotong dengan blender }\end{array}$ & 4 & 4 & 4 \\
\hline $\mathbf{4}$ & $\begin{array}{l}\text { Menyaring hasil blenderan rimpang jahe sehingga } \\
\text { diperoleh ekstrak jahe }\end{array}$ & 4 & 3 & 4 \\
\hline $\mathbf{5}$ & $\begin{array}{l}\text { Memanaskan ekstrak jahe dalam wajan sambil diaduk } \\
\text { sampai diperoleh serbuk jahe }\end{array}$ & 4 & 4 & 4 \\
\hline $\mathbf{6}$ & $\begin{array}{l}\text { Mengayak serbuk jahe yang diperoleh sehingga } \\
\text { diperoleh serbuk yang halus }\end{array}$ & 3 & 4 & 4 \\
\hline $\mathbf{7}$ & \begin{tabular}{l} 
Menyajikan minuman serbuk jahe instan \\
\hline
\end{tabular}
\end{tabular}

Tabel 2. Penilaian Keterampilan Pembuatan Serbuk Keji Beling Instan

\begin{tabular}{|c|c|c|c|c|}
\hline No & Komponen yang diamati & \multicolumn{3}{|c|}{ Skor Penilai } \\
\hline 1 & Mencuci simplisia keji beling & 4 & 4 & 4 \\
\hline 2 & Memanaskan campuran keji beling dan air dalam panci & 4 & 4 & 4 \\
\hline 3 & $\begin{array}{l}\text { Menyaring ekstrak keji beling dan dimasukkan ke } \\
\text { dalam wajan }\end{array}$ & 4 & 4 & 4 \\
\hline 4 & $\begin{array}{l}\text { Memanaskan ekstrak keji beling dalam wajan sambil } \\
\text { diaduk sampai diperoleh serbuk keji beling }\end{array}$ & 4 & 4 & 4 \\
\hline 5 & $\begin{array}{l}\text { Mengayak serbuk keji beling yang diperoleh sehingga } \\
\text { diperoleh serbuk yang halus }\end{array}$ & 4 & 4 & 4 \\
\hline 6 & Menyajikan minuman serbuk keji beling instan & 4 & 4 & 4 \\
\hline 7 & Mencuci simplisia keji beling & 4 & 4 & 3 \\
\hline
\end{tabular}

Tabel 3. Penilaian Keterampilan Pembuatan Serbuk Secang Instan

\begin{tabular}{c|l|c|c|c}
\hline No & \multicolumn{1}{c}{ Komponen yang diamati } & \multicolumn{3}{c}{ Skor Penilai } \\
\hline $\mathbf{1}$ & Mencuci serutan kayu secang & 4 & 4 & 4 \\
\hline $\mathbf{2}$ & $\begin{array}{l}\text { Memanaskan campuran serutan kayu secang dan } \\
\text { air dalam panci }\end{array}$ & 4 & 4 & 4 \\
\hline $\mathbf{3}$ & $\begin{array}{l}\text { Menyaring ekstrak kayu secang dan dimasukkan } \\
\text { ke dalam wajan }\end{array}$ & 4 & 4 & 4 \\
\hline $\mathbf{4}$ & $\begin{array}{l}\text { Memanaskan ekstrak kayu secang dalam wajan } \\
\text { sambil diaduk sampai diperoleh serbuk temulawak }\end{array}$ & 4 & 4 & 4 \\
\hline
\end{tabular}




\begin{tabular}{c|l|c|c|c}
\hline No & \multicolumn{1}{c}{ Komponen yang diamati } & \multicolumn{3}{c}{ Skor Penilai } \\
\hline $\mathbf{5}$ & $\begin{array}{l}\text { Mengayak serbuk secang yang diperoleh sehingga } \\
\text { diperoleh serbuk yang halus }\end{array}$ & 4 & 4 & 4 \\
\hline $\mathbf{6}$ & Menyajikan minuman serbuk secang instan & 4 & 4 & 4 \\
\hline $\mathbf{7}$ & Mencuci serutan kayu secang & 4 & 4 & 3 \\
\hline
\end{tabular}

Berdasarkan tabel 5.1; 5.2; dan 5.3 di atas tampak bahwa peserta pelatihan mengikuti dengan sungguh-sungguh dan antusias dalam mengikuti instruksi baik yang diberikan buku petunjuk pembuatan minuman herbal maupun oleh pembimbing. Dimana terlihat bahwa skor peserta didik untuk setiap keterampilan membuat minuman serbuk herbal kesehatan memperoleh skor rata-rata di atas 3.5.
Setelah kegiatan pelatihan peserta pelatihan diberikan instrument angket respon. Repon peserta pelatihan pada kegiatan PKM pembuatan minuman herbal kesehatan sangatlah positip karena di atas $90 \%$ memberikan jawaban sangatlah positip dan sisanya merepon cukup positip. Respon peserta pelatihan secara detail dapat dilihat pada Tabel 4 di bawah ini.

Tabel 4. Data Angket Peserta pelatihan

\begin{tabular}{|c|c|c|}
\hline No & Komponen yang diamati & Jwb (\%) \\
\hline \multirow{5}{*}{1} & Mengapa saudara mengikuti kegiatan pelatihan ini? & \\
\hline & A. Diperintahkan oleh perangkat RT/ RW & \\
\hline & B. Mengikuti ajakan teman & 6,7 \\
\hline & C. Ingin memperoleh sumbangan & \\
\hline & D. Ingin menambah keterampilan & $93,5 \%$ \\
\hline \multirow{5}{*}{2} & $\begin{array}{l}\text { Bagaimana sikap keluarga dengan keikutsertaan saudara pada } \\
\text { kegiatan pelatihan ini? }\end{array}$ & \\
\hline & A. Sangat mendukung & 93,5 \\
\hline & B. Mendukung & 6,7 \\
\hline & C. Kurang mendukung & \\
\hline & D. Tidak mendukung & \\
\hline \multirow{5}{*}{3} & $\begin{array}{l}\text { Menurut pendapat saudara, bagaimana penyelenggaraan } \\
\text { kegiatan pelatihan ini? }\end{array}$ & \\
\hline & A. Sangat baik & 93,5 \\
\hline & B. Baik & 6,7 \\
\hline & C. Kurang baik & \\
\hline & D. Tidak baik & \\
\hline \multirow{5}{*}{4} & Apakah kegiatan pelatihan ini menarik bagi anda? & \\
\hline & A. Sangat menarik & 100 \\
\hline & B. Menarik & \\
\hline & C. Kurang menarik & \\
\hline & D. Tidak menarik & \\
\hline \multirow{5}{*}{5} & Apakah kegiatan pelatihan ini bermanfaat bagi anda? & \\
\hline & A. Sangat bermanfaat & 100 \\
\hline & B. Bermanfaat & \\
\hline & C. Kurang bermanfaat & \\
\hline & D. Tidak bermanfaat & \\
\hline \multirow{5}{*}{6} & $\begin{array}{l}\text { Bagaimana pengetahuan dan keterampilan saudara setelah } \\
\text { mengikuti kegiatan pelatihan ini? }\end{array}$ & \\
\hline & A. Sangat meningkat & 93,5 \\
\hline & B. Meningkat & 6,7 \\
\hline & C. Kurang meningkat & \\
\hline & D. Tidak ada perubahan & \\
\hline
\end{tabular}




\begin{tabular}{|c|c|c|c|}
\hline No & \multicolumn{2}{|c|}{ Komponen yang diamati } & Jwb (\%) \\
\hline \multirow{5}{*}{7} & \multicolumn{2}{|c|}{$\begin{array}{l}\text { Apakah anda yakin dapat melanjutkan hasil kegiatan pelatihan } \\
\text { ini di rumah? }\end{array}$} & \\
\hline & \multicolumn{2}{|l|}{ A. Sangat yakin } & 90 \\
\hline & \multicolumn{2}{|l|}{ B. Yakin } & 10 \\
\hline & \multicolumn{2}{|l|}{ C. Kurang yakin } & \\
\hline & \multicolumn{2}{|l|}{ D. Tidak yakin } & \\
\hline \multirow{5}{*}{8} & \multicolumn{2}{|c|}{$\begin{array}{l}\text { Apakah sebelumnya anda pernah mengikuti kegiatan pelatihan } \\
\text { semacam ini? }\end{array}$} & \\
\hline & \multicolumn{2}{|l|}{ A. Sangat sering } & \\
\hline & \multicolumn{2}{|l|}{ B. Sering } & \\
\hline & \multicolumn{2}{|l|}{ C. Jarang } & $10 \%$ \\
\hline & \multicolumn{2}{|l|}{ D. Tidak pernah } & $90 \%$ \\
\hline \multirow{5}{*}{9} & \multicolumn{2}{|c|}{$\begin{array}{l}\text { Bagaimana tanggapan anda terhadap materi yang disampaikan } \\
\text { narasumber? }\end{array}$} & \\
\hline & \multicolumn{2}{|l|}{ A. Sangat mudah dipahami } & 96,7 \\
\hline & \multicolumn{2}{|l|}{ B. Mudah dipahami } & $3,3 \%$ \\
\hline & \multicolumn{2}{|l|}{ C. Cukup mudah dipahami } & \\
\hline & \multicolumn{2}{|l|}{ D. Sulit dipahami } & \\
\hline \multirow{4}{*}{10} & \multicolumn{2}{|c|}{$\begin{array}{l}\text { Manakah di antara kegiatan pelatihan hari ini yang anda sukai? } \\
\text { (Boleh dipilih lebih dari satu) }\end{array}$} & \\
\hline & \multicolumn{2}{|c|}{ A. Pembuatan minuman serbuk jahe instan } & 30 \\
\hline & \multicolumn{2}{|c|}{ B. Pembuatan minuman serbuk secang instan } & 30 \\
\hline & \multicolumn{2}{|c|}{ C. Pembuatan minuman serbuk keji beling instan } & 40 \\
\hline \multicolumn{4}{|c|}{$\begin{array}{ll}\text { Berdasarkan data dari angket peserta } & \text { b. } \\
\text { pelatihan bahwa peserta pelatihan pada } & \text { tangga warga desa Jajar, Kec. } \\
\text { dasarnya merasa terkesan dengan adanya } & \text { Talun, Blitar terhadap wirausaha, } \\
\text { pelatihan pembuatan minuman herbal } & \text { manajemen usaha, serta teknik } \\
\text { kesehatan. Selain itu peserta pelatihan juga } & \text { pengemasan produk minuman } \\
\text { merasa adanya peningkatan pada ranah } & \text { serbuk herbal instan mengalami } \\
\text { pengetahuan dan keterampilan dalam } & \text { peningkatan (hasil angket dan } \\
\text { membuat minuman herbal kesehatan. } & \text { wawancara peserta pelatihan). }\end{array}$} \\
\hline
\end{tabular}
angket respon didukung dengan wawancara, dimana berdasarkan hasil wawancara merasa sangat senang adanya pelatihan yang memiliki dampak terhadap penambahan pendapatan perekonomian rumah tangga. Dan pelatihan yang dapat menambah pengetahuan, pemahaman, dan keterampilan tentang pembuatan minum herbal kesehatan. di atas.

\section{PENUTUP}

\section{Simpulan}

Berdasarkan analisis data di atas, maka dapat disimpulkan bahwa:

a. keterampilan para ibu rumah tangga warga desa Jajar, Kec. Talun, Blitar dalam membuat minuman serbuk herbal instan setelah mengikuti kegiatan pelatihan mengalami peningkatan (sesuai dengan hasil angket peserta pelatihan)

\section{Saran}

a. Perlu adanya pelatihan yang berkelanjutan untuk pengemasan serbuk minuman herbal kesehatan agar memiliki nilai juga yang pantas

b. Perlu adanya pelatihan herbal kesehatan untuk jenis-jenis herbal yang lain

\section{DAFTAR PUSTAKA}

Achmad, S.A., Hakim, E.H., Makmur, L, Syah, Y.M,, Juliawaty, L,D, Mujahidin, D. (2007). IImu Kimia dan Kegunaan Tumbuh-Tumbuhan Obat Indonesia. Jilid 1. Bandung: Penerbit ITB.

Angria, M. (2013). Pembuatan Minuman Instan Pegagan (Centella asiatica) dengan Cita Rasa Cassia vera. Padang: Prodi Teknologi Hasil Pertanian. 
Anonim. (2013). Jamu Instant Ala Sumarni. http://kesehatan.kompasiana.com/alter natif/2012/09/07/jamu-instan-alasumarni-491080.html. Diakses tanggal 10 Januari 2013.

Handra, H. (2005). Jamu Toga dan Apikasinya dalam Rumah Tangga. http://kepegawaian.unpad.ac.id/info_d etail.aspx?id=2. Diakses tanggal 4 Maret 2014.

Heyne K. (1987). Tumbuhan Berguna Indonesia. Jilid 1. Jakarta : Departemen Kehutanan.

Mallaleng, H.R., Purwaningtyas, U., Hermawati, R., Solichah, N., Syah, F.Z.N. (2011). Tanaman Obat untuk Penyakit Sindrom Metabolisme. Malang: UM Press. I

Mallaleng, H.R., Purwaningtyas, U., Hermawati, R., Solichah, N. (2012). Katalog Tumbuhan Obat Alam. Jilid 1. Batu: UPT Materia Medica Batu.

Manitto, P. (1992). Biosintesis Produk Alami. Cetakan I. Penerjemah Koensoemardiyah. Semarang: IKIP Semarang Press. 1

Suyatno (2011). Potensi Tumbuhan Paku Indonesia sebagai Bahan Baku Fitofarmaka. Pidato Pengukuhan Guru Besar. Blitar: Unesa University Press. 